\title{
Civil Society Meta-Organizations and Legitimating Processes The case of the addiction field in France
}

\section{Laurent, A., Garaudel, P., Schmidt, G., \& Eynaud, P. Civil Society Meta-organizations and Legitimating Processes: the Case of the Addiction Field in France. VOLUNTAS: International Journal of Voluntary and Nonprofit Organizations, 1-20.}

\begin{abstract}
:
To cope with the new challenges inherent to their political role, Civil Society Organizations (CSOs) must convince their stakeholders about their legitimacy, and meta-organizations (MOs) appear to play a central role in such a context (Arhne \& Brunsson, 2005; Bonfils, 2011). In this paper, we aim to better understand the legitimating processes of a specific kind of MOs - namely Civil Society MOs (CSMOs) -, considering that CSMOs feature some characteristics that reinforce both internal and external legitimacy issues. Our research is based on an in-depth case study of a French national federation (Fédération Addiction) formed by the merger of two former federations originating in different fields, alcoholism treatment and drug addiction professionals. We confirm the importance of stakeholders' representativeness in the governance of MOs and especially in multi-stakeholders CSMOs, and we corroborate the assertion that MOs closely relate to categorization-related issues and the categorization process itself in many ways: the legitimacy and the potential for action of MOs depend on the socially perceived appropriateness of the delimitation of the field that they claim to represent, and at the same time categorization is reinforced by the creation of MOs. We contribute to the current literature on MOs in two main ways. First, we show how a change in the relevant categorization may result from the dual and interacting actions of the MOs themselves and public authorities. Second, our case study illustrates how a restructuring of the MOs landscape may strengthen the salience of internal le gitimacy issues federative actors are confronted with in order to maintain their representativeness and position in the expanded organizational field. In this dynamic context, external and internal legitimating processes appear closely intricate, and categorization and governance issues appear strongly interrelated.
\end{abstract}

Key-words: Legitimacy, legitimating process, meta-organizations, civil society organizations, merger, addictions, addictology

\section{Introduction}

The "network society" perspective has become a major topic in the literature on public governance, highlighting the significant role that civil society actors may play both in the decision-making and the implementation processes of public policy (Bovaird 2005; Bang and Esmark 2009). To cope with the new challenges inherent to this political role, however, civil 
society organizations (CSOs) must convince different key stakeholders about their legitimacy and prove that they can significantly and efficiently contribute to common goods. With regard to this widened view of the public policy-making process, involving strong interactions between public and private actors, meta-organizations (MOs) often appear to play a central role (Bonfils, 2011). In a seminal paper, Arhne and Brunsson (2005) define MOs as organizations whose members are organizations. MOs seem to be well-suited when it comes to coordinating the various interests of the stakeholders involved within a given field and act as a legitimate and collective voice to address public authorities (Rajwani, Lawton and Phillips, 2015).

Strikingly enough, on a micro-level, the way organizations in general build their legitimacy has been under-researched, in contrast with the huge amount of theoretical debate about the concept of legitimacy itself (Meyer, Buber and Aghamanoukjan, 2013). Even more, in the current growing literature about MOs, the legitimacy question often remains an implicit issue rather than an explicit, empirical, and theoretical issue. Berkowitz and Dumez (2015) nevertheless provide an interesting empirical study of MOs in the oil and gas industry, which leads them to argue about the various sources of legitimacy that are critical for MOs as strategic actors. But it is not their intention to unveil the mechanisms underlying the legitimation process itself. Besides, on a meso-level, MOs often emerge spontaneously from the regrouping of organizations that perceive themselves as belonging to the same organizational field and share sufficiently common interests to do so. Hence the fact that MOs have much to do with the concept of "categorization" (Dumez 2008): organizations create and enter a $\mathrm{MO}$ in order to be more powerful within a given category in their field, and at the same time categorization is reinforced by the creation of MOs. But neither the way categories are emerging and are becoming accepted, nor the roles of specific actors and factors in that process have been much investigated in the MO literature. It may also be that the drivers for change come from major evolutions in the economic or institutional environment, which may weaken the legitimacy of the current categorization underpinning the meta-organization. This in turn can induce a change in the underlying categorization and in the meta-organization's self-definition: Dumez (2008) gives an example in the for-profit sector, the "perfumery industries federation," which became the "beauty businesses federation." The underlying categorization, or even sometimes the very existence of MOs - especially civil society MOs closely related to public policy in a given societal area - may result from the actions of public authorities. Karlberg and Jacobsson (2015) explore this issue in a European perspective 
with the case study of an umbrella organization operating at the European level, the European Women's Lobby (EWL). The potential role of public authorities as originators of MOs is also pointed out by Brankovic (2018). She notes that meta-organizations consist in attempts to introduce order in society which may come from organizations themselves, but also from the authorities seeking to have a little more organization under their jurisdiction. According to the author, both for focal organizations and third parties, once-established, associations are, on the on hand, expected to decrease uncertainty and complexity, and, on the other, increase control and predictability.

In this paper, we aim to better understand the legitimating processes of MOs. We investigate a specific kind of MOs — namely Civil Society MOs (CSMOs) —, considering that CSMOs feature some characteristics that reinforce both internal and external legitimacy issues. Our research is based on an in-depth case study of a French national federation (Fédération Addiction) formed by the merger of two former federations originating in different fields, alcoholism treatment and drug addiction professionals. The distinction between alcoholism and drug addiction was dramatically challenged by a public policy shift in the period 1999-2008, aiming at creating centers dealing with addiction behaviors in general. This resulted in the merger of the two federations. However, at the same time, the new merged federation faced some internal issues that compelled its decision-makers to engage in a significant democratizing process and to open up to new types of stakeholders. We show how the evolution of public policy creates some new challenges in terms of external legitimacy within the field and led to redefine the field's categorization; we also highlight how the reconfiguration of the CSMO's governance pertains to an internal legitimating process. The article is structured as follows. First, we draw on the academic literature about (CS)MOs and about legitimating processes to specify our research question. Second, we present the context of our case study, our research design and provide a detailed narrative of the case. The main results and theoretical implications are discussed in the third and final section.

\section{Literature review and research question}

\section{Defining and discussing the concept of Meta-Organisations (MO)}

The concept of MO is not easy to grasp with regard to its positioning in the vast field of organization theory. The term has been only recently coined by Ahrne and Brunsson (2005, 2008), who fundamentally characterise MO as organizations with other organizations as members, by opposition to individual-based organizations. Nevertheless, some connection 
may be found between MOs and other organizational forms, such as federations, confederations, multi-level associations, umbrella organizations, intermediaries or unconventional organizations (Einarson, 2012; Young, 2001 ; Karlberg and Jacobsson, 2015; Frandsen and Johansen, 2015 ; Brès, Raufflet and Boghossian, 2017). Most significantly, Arhne and Brunsson subsequently developed a theoretical perspective centered on the concept of partial organizations (Arhne and Brunsson, 2011), by opposition to formal and complete organizations which have simultaneously access to five core elements of organizations (membership, hierarchy, rules, monitoring and sanction). From this perspective, MOs may often be conceived as formal but incomplete organizations.

The concept of MO relates to various empirical organizational forms that have been widely investigated for themselves, with or without any explicit reference to the MO concept, such as trade associations (König, Schulte and Enders, 2012; Berkowitz and Dumez, 2015; Berkowitz and Bor, 2017; Lawton, Rajwani, and Minto, 2017) or international organizations (Kerwer, 2013; Ahrne, Brunsson, and Kerwer, 2016; Brankovic, 2018). This diversity makes difficult the generalization of empirical results based on a specific type to all kinds of MOs. For instance, what can be observed for the European Union (implying a strong juridical and political dimension) may not necessarily be relevant for the analysis of Global Union Federations (which are highly dependent of and have few formal power on their national trade union members; Cotton and Gumbrell-McCormick, 2012) or sport federation (which conversely have more power and ability to impose their decision on sport club members). If driven with the aim of contributing to MO theory, the study of a specific type of MO consequently implies to determine what fundamental characteristics it shares with most MOs, and what are the peculiarities of the specific form investigated.

Conversely, more and more authors have recently tended to use the term MO with few or no mention of Ahrne's and Brunsson's theoretical framework (see Gulati, Puranam, and Tuchman, 2012; Lawton, Rajwani, and Minto, 2017; Spillman, 2017; Radnejad, Vredenburg, and Woiceshyn, 2017), leading to distinguish the "European school" of MO, building on Ahrne and Brunsson work, from a more US-UK based research community having the seminal paper by Gulati, Puranam, and Tushman (2012) as their key reference (Ahrne, Brunsson and Seidl, 2016; Berkowitz and Bor, 2017). As a fact, the perspective developed by Gulati and al., focused on the idea of meta-organizational design, has much more to do with the network perspective, with a specific stress on corporate networks and some other concepts such as the extended-enterprise, the closed community, the open community (public forum) and the managed eco-system models. 
The perspective developed by Arhne and Brunsson invites to adopt a renewed and more indepth view on the MO phenomena. Indeed, a significant part of the previous works has adopted a more relational, interorganizational, network or collective action perspective rather than adopting a focus on the formal organization specifically in charge of coordinating and regulating relationships among organization members and/or to act as an "intermediary" (Frandsen and Johansen, 2015) with a "mediating" role between members and external stakeholders: the central formal organization is a mere "coordinating tool" or "governance device" rather than a specific organizational object that fully deserves academic investigation for itself. By contrast, MO theorists acknowledge that MOs are endowed with some degree of "actorhood" (Ahrne, Brunsson, and Kerwer, 2016) and that most are striving for increasing their autonomy and their decision-making power. This change in the focus of interest is clearly illustrated by the notion of "secretariat" (Ahrne and Brunsson, 2008; Gadille, Tremblay and Vion, 2013) which relates to the formal structure composed of permanent employees continuously carrying out its "meta-organizational" mission, while organization members tend to have only discontinued relationships.

\section{Typifying Civil Society MOs (CSMOs)}

The specific kind of MO we investigate in this paper may be referred to under the label of Civil Society Meta-Organization (CSMO). We use this term in a way quite similar to Karlberg and Jacobsson (2015) in their study of the European Women's Lobby (EWL): they use the term "Civil Society Umbrella Organization", but explicitly conceptualize Umbrella Organizations in terms of MOs. We prefer to use the term CSMO for at least two main reasons. First, it unambiguously positions our research within the growing strand of literature about MOs. Second, the term Umbrella Organization may suggest the regrouping of relatively homogenous entities with regard to their very nature. For example, all EWL members are women's associations even if they may differ greatly with regard to their specific goals, strategies or political stances (Karlberg and Jacobsson, 2015). This homogeneity of members may also be observed when an umbrella $\mathrm{MO}$ is composed of organizations operating at a lesser territorial level - for example, a European federation regrouping national federations (Young, 2001; Einarson, 2012). By contrast, some MOs are characterized by the presence of members of very different nature. MOs do not necessarily have only organizations as members: for example, national sport federations may have both clubs and individual affiliated members. Moreover, there may exist strong differences among the organizations involved in a same MO (private companies, nonprofit organizations, public entities as 
universities or hospitals, territorial authorities or even other MOs). The possible coexistence of different types of stakeholders has thus given way to the notion of "multi-stakeholders MOs" (Berkowitz and Dumez, 2015).

The "civil society" component of CSMOs also calls for some clarification. The notion of civil society refers to the notions of "third sector", "non-governmental organizations (NGO)' or "non-profit organizations (NPO)". In this paper, the notion of CSMO refers less to the common nature of the MO members than to the societal dimension of the underlying organizational field or strategic action field (Fligstein and McAdam, 2011) and to the strong interactions existing between the MO and the public policy related to this field. This points to the fact that some MOs, as highlighted by Bonfils (2011) with its investigation of the Disabled Peoples Organizations Denmark (DPOD), are in a position to play a major role in the decision-making process and the implementation of public policy in areas that have a strong societal impact and/or contribute to the common good. Those CSMOs are often multistakeholders MOs, that is MOs regrouping various kinds of stakeholders with different interests in the field, even if non-profit organizations often play a prominent role.

\section{Identifying legitimacy and legitimating issues of CSOs}

Generally speaking, legitimacy can be understood as a strategic asset, a condition to achieve organizational goals and to generate the resources needed to operate (Bailey and Koney 2000; Pfeffer and Salancik 1978). The concept of legitimacy, however, has been widely debated in the literature and it requires conceptual refinement. Suchman (1995) defines legitimacy as "a generalized perception or assumption that the actions of an entity are desirable, proper, or appropriate within some socially constructed system of norms, values, beliefs, and definitions." Many authors draw on the distinction between pragmatic, normative and cognitive legitimacy. Pragmatic legitimacy relies on the ability to meet the interest of the organization's most immediate audiences (Suchman 1995). Normative legitimacy has a moral basis and rests on the congruence with "the shared value premises that structure collective assessments of the good and the bad" (Deephouse and Suchman 2008). Cognitive legitimacy reflects "the extent to which an organization and its activities are culturally supported and conceptually correct, i.e., the degree to which a firm's actions are taken for granted" (Wang 2010). As Johnson (2004) states, there is a vast array of objects potentially concerned by legitimation: "an act, a rule, a procedure, a routine, a distribution, a position, a group or team, a group's status structure, teamwork, a system of positions, an authority structure, an organization, organizational symbols, an organization's form [...] (to name a few)." 
Those general features and dimensions of legitimacy echo with some central issues CSOs are currently facing, due to stronger pressures, the development of managerialism (Meyer et al. 2013), and their increasingly central role in coping with worldwide societal challenges, hence high expectations in terms of legitimacy. As Brown (2008) puts it, "[to] fulfil this promise, CSOs must themselves grapple with clarifying their legitimacy as social and political actors and their accountabilities to key stakeholders that ensure that they contribute to the public good." In a world where market logic and the commodification process tend to be hegemonic, legitimacy is a means for CSOs to make a better claim for their specific identity and to strive more successfully for resources. Through legitimacy, CSOs can be confident they are doing the right thing and are involved in a self-selected quest for standards of action (Pallas, Gethings and Harris 2015).

This assumes that legitimacy is double-sided and actually draws on two perspectives, internal and external: internally, it can be seen as a key driver for action; externally, legitimacy can help balance external pressures better. From the first perspective, legitimacy is driven by CSOs through desirable ideas and core values (Meyer et al. 2013): CSOs' legitimacy starts with their projects and may depend, for example, on "their ability to give users a voice, to elicit voluntary commitment from a variety of sources, to mobilize and cultivate the social capital that stems from supportive relations in civil society" (Evers and Laville 2004). From the second perspective, legitimacy can be perceived as a "roof" that will protect CSOs against crises (Meyer et al. 2013). For example, if a CSO is short of financial resources, it may be tempted to transform its legitimacy to keep receiving funding (Powell and Friedkin 1987), especially from the government.

Thus, the issue of CSOs' legitimacy in the eyes of public agencies is particularly acute in countries that rely on the provision of strong public services. In France, CSOs were closely linked to the development of the welfare state during the $20^{\text {th }}$ century, providing publicly funded services in the fields of health, social, sport or cultural activities, for example. As a result of the recent decrease in public funding, CSOs have been obliged to restructure and group. Along with decisions to merge or to pool activities, legitimacy has become a more collective issue and has to be approached through the actions of the various CSOs working in the same field. More specifically, over the last two decades, most French CSOs have been organized around national federations that aim to be national representatives toward the centralized State. With the combined impact of decentralization, higher competition for financial resources, and CSO mergers, this pattern is currently being challenged. Legitimacy now has to be addressed collectively, while CSOs are experiencing new forms of 
collaboration at the local level to deal with local authorities. In this context, the role of MOs is being regenerated and becoming crucial in the new institutional environment.

\section{Legitimating processes of (CS)MOs : internal and external legitimacy at stake}

MOs present some distinctive features that make the issue of legitimacy crucial, both in terms of the specific functions of MOs and in terms of their usually prevailing decisionmaking processes. Perhaps even more so than for CSOs and organizations in general, the critical importance of legitimacy may be usefully accounted for with reference to the dual dimension, internal and external, of legitimacy. This relates to the distinction between "inward" and "outward" functions of MOs. One of the ultimate goals pursued by MOs is to serve the interests of their members. In close connection with this, the explicit purpose of MOs is to defend the industry's interests (in the case of trade associations) or the interests of the activity sector to which they belong. More specifically, in order to meet this goal, MOs can have a wide variety of functions (Berkowitz and Bor, 2017). Ahrne and Brunsson (2008) identify three general purposes for which a MO may be set up: interaction among members, collective action among members, or creation of a collective identity. Berkowitz (2016) highlights the information production function of MOs to support each of these purposes and also identifies a wide variety of goals for MOs (lobbying, etc). Lawton, Rajwani, and Minto (2017) note that, as member-driven organizations, trade associations seek to improve the conditions of members' business environment by pursuing policy initiatives and managing issues of reputation and legitimacy; from a sociological perspective, they also provide an arena for social construction of meaning and to allow members to build a shared perspective on their market activities. However, beyond their great diversity, much of the functions identified in the literature may be classified according to whether they relate to cooperation, coordination and regulation among members (i.e., the inward functions of MOs), or whether they relate to the management of relationships with external stakeholders such as NGOs, policy-makers, etc. (ie, the outward functions of MOs). Even if many interactions exist between inward and outward functions, we suggest that inward functions are more concerned with internal legitimacy issues, while outward functions are more concerned with external legitimacy issues.

The quest for internal legitimacy, and governance issues

Internal legitimacy is a crucial dimension for MOs in order to securing and strengthening the support of its internal members. With regard to the classical typology of 
Suchman (1995) it may be argued that, along with the pragmatic component (relating to the ability to meet the interest of the organization's most immediate audiences, that is its organization members in the case of MOs), moral legitimacy is a strong component of MOs' internal legitimacy. In general, moral legitimacy takes one of three forms: evaluations of outputs and consequences (linked to consequential legitimacy); evaluations of techniques and procedures (linked to procedural legitimacy); and evaluations of categories and structures (linked to structural legitimacy). As well as consequential legitimacy, the procedural and structural dimensions appear to be of particular importance in the case of MOs. The crucial importance of internal legitimacy greatly results from the "structural weakness" of MO highlighted by Ahrne and Brunsson. Meta-organizations tend to be highly dependent on their singular members (Arhne and Brunsson, 2010). Moreover, they often tend to have no choice but to make decisions by consensus, as their decision-making processes do not rest on a clear hierarchy (Arhne and Brunsson, 2008). With regard to this lack of formal authority over its members, the level of legitimacy perceived by its internal constituents will be of particular importance when the MO seeks to produce some voluntary self-regulation in the form of standards or industry norms.

As suggested in the literature, governance is one of the central issues that determine the internal legitimacy dimension of MOs. Boléat (2003) notes that one of the three common characteristics of trade associations is that they exhibit a governance and decision-making structure that is representative of their members. Gadille, Tremblay and Vion (2013) analyze the role of the "secretariat" in some specific kinds of organized French territorial clusters / network organizations, and suggest that their meta-organizational role involves managing four types of relationships: secretariat/organization members, secretariat/staff members, organization members/organization members, staff members/staff members. Ehlinger, Perret and Chabaud (2007) highlight the need for legitimacy in territorial network organizations in order to better succeed in its "meta-manager" mission, orchestrating the collaboration between private and public actors on a given territory. The legitimacy issue is all the more important that the fulfillment of this role implies a delegation of decision power from actors unwilling to give up their autonomy. They identify several conditions of legitimacy for securing the support of organization members and their approval of the secretariat decisions: the possibility that the decisions may be reassessed, the possibility for the members to give directive, a decision-making process reflecting the diversity of internal members, etc. The territorial MOs investigated by Ehlinger, Perret and Chabaud correspond to multishareholders MOs operating in the specific French context. However, they cannot be labeled 
as CSMOs since their goal is more concerned with economic competitiveness and territorial development. Besides, they result from a political initiative and a deliberate approach of public authorities, and public authorities are generally internal members in their own right, with an active and explicit role in the governance process. This contrasts with the national federation we studied, for which public authorities may be better considered as prominent but external stakeholders, interacting in a face-to-face way with the federation.

The quest for external legitimacy, and categorization issues

In line with the collective action purpose pointed out by Ahrne and Brunsson, a more specific but important role of MOs is to act as a "voice" for actors in the field (Rajwani et al. 2015). As this has been highlighted in the case of trade associations (Boléat 1996; Rajwani et al. 2015), MOs often act as a representative or collective body, engaging with government regulators and policy makers, medias, and other opinion formers. This role requires a great deal of legitimacy to be performed successfully. Different kinds of legitimacy have to be managed in order to be given the status of a representative actor and to be perceived as legitimate to represent an entire class of actors in a field.

An obvious but critical prerequisite relates to the socially perceived appropriateness of the delimitation of the field that the MO claims to represent. As Dumez (2008) noted, the creation of a MO has a lot to do with issues of identity and categorization, given that MOs regroup a category of members who consider that they share a common identity trait. The way a category is self-defined is especially critical if external stakeholders — in particular, public authorities, are to recognize the MO as the appropriate representative body to discuss a given issue. This is all the more critical when several MOs can concurrently claim to be a relevant interlocutor and when, beyond the specific interests of the members, the issues at stake may have important consequences at a political or societal level. This importance can also be expressed with regard to Suchman's typology as it appears that a cognitive or taken-forgranted type of legitimacy in relation to the underlying categorization on which a MO is based determines its ability to fully perform its external function as a representative of its members.

According to Ahrne, Brunsson and Seidl (2016), one of the five fundamental dimensions of complete organizations relates to memberships: "It is necessary for those involved in the interaction to know who else is involved. In organization this is accomplished through decisions on membership, defining who is a member and who is not." (p.3). Ahrne et al. even claim that it is the most salient organizational element in MOs (p.5). Membership is closely connected with categorization, but is a more encompassing dimension that relates to 
other important issues such as the specific goals pursued, the ability to influence members, the efficacy of collective action, etc. In relation with these different issues, membership is also an important dimension contributing to the MO legitimacy. Among the scant research empirically investigating the issue of legitimacy at a meta-organizational level is the study by Berkowitz and Dumez (2015): in their analysis of MOs in the oil and gas industry, they propose some sources of legitimacy that are critical for MOs as strategic actors. They insist on the strategic dimension of membership choice, that is, the way a MO selects and recruits its members. The sources of legitimacy are varied, however, and Berkowitz and Dumez acknowledge that they can differ according to the specific type of meta-organization at stake. In particular, much depends on whether the MO seeks to cover a whole class of members, or to remain a selective club.

The variety of possible approaches in terms of strategic membership has also been highlighted by Brankovic (2018) in her study on University associations. According to the author, identity of an MO could be better described as the common denominator of organizational identities of all its members. For example, universities can group together on a geographical basis, a confessional basis, a disciplinary basis, a status-driven basis, etc. It follows from this, as it is especially obvious in the case of status-driven associations, that MOs do not necessarily seek completeness and class saturation. The plurality of possible categorization criteria also explains why several MOs may coexist in the same organizational field and why one organization may belong to several different MOs.

Based on the extant literature, we consider that CSMOs feature some characteristics that reinforce both internal and external legitimacy issues. By examining categorization issues at the level of a field where CSMOs play a central role, and governance issues at the organizational level, we can gain insight into the external and internal legitimating processes that prevail, as well as into their interactions. We present in the following section our research design and the narrative of our case study in the field of addiction in France .

\section{Empirical setting: an in-depth case study of a French federation in the field of addictions}

\section{The context: from a reconfiguration of a field to a redefinition of the federative level}

The concept of addiction was elaborated in the course of the 1990s by neurologists and psychiatrists. The institutionalization of this concept and its appropriation by French public 
authorities has followed a complex path (Fortané, 2011). Addictology is a new approach, reflecting the need to involve all public health professionals working in addictions. It is a break with the framework for actions and policies that had previously prevailed. This approach grasps "a broad spectrum of social phenomena in an innovative way," by including "a vast continent of hitherto heterogeneous behaviors, ranging from simple consumption to the most devastating addiction," subsequently called "addictive behaviors" (Fortané 2011). Before the concept of addictology was institutionalized and implemented through public policy, the issues of alcohol, tobacco, and illicit drugs were separated both in the structure of the health care system and in the configuration of public administration.

The addictology approach started to develop in France in the early 1990s, following the activities of a few psychiatrists and a diversity of researchers and professionals in the field of epidemiology, alcohology, drug addiction, and public health. The concept finally gained "academic prestige" (Fortané, 2011) after it was linked to the neurobiological theory of the dopamine hypothesis of reward, creating common ground for the diversity of addictive behaviors. Since the 1970's, public policies had relied on the division and autonomy of "drug" and "alcohol" problems. This stemmed mainly from the differentiation of their legal status (alcohol was excluded from the list of illicit substances), which made it impossible to take the same kind of public action to deal with both problems. As a consequence, the centers in charge of taking care of alcoholics and drug addicts ("toxicomanes") were legally distinct.

This division was questioned after addictions were recognized as a public policy issue. This was realized through the enactment of a three-year plan adopted by the French government in 1999 and the creation of a special inter-ministerial committee to coordinate health, security, and social issues raised by addiction. This plan was followed by the law of the January 2, 2002, which entailed the restructuring of the field and aimed to create a unique financial and legal framework to take into account people suffering from addiction. The law enforced the creation of general addiction centres (CSAPAs), and put end to the two former statuses of existing centres (specialized in drug or alcohol issues). Those centers are managed either by public hospitals or by private associations. The CSAPA status sanctions the fact that the separation between users of licit and illicit drugs was no longer considered justifiable. The 2002 law also incorporated those centers into the general organization and financing of the French health care system.

The significant evolutions of the public health policy in relation with drug and alcohol issues have thus led to a reconfiguration of the related organizational fields and a change in 
the predominant categories upon which public policy was based. Such a context offered us a great opportunity to investigate the impact of field reconfiguration and change in the categories structuring public policy on the MOs' landscape and, more specifically, to examine how MOs responded to a new structuration of the field that was contributing to undermine the relevance of the categories to which they were historically linked. The underlying categorization of MOs is one of their most critical attributes that determined both their very organizational identity and, correlatively, the way they can efficiently fulfill their various inward and outward meta-organizational functions.

\section{The research design}

As outlined previously, we aim to better understand the legitimating processes at stake in MOs, especially in CSMOs, both in their internal and external dimensions. Our research question requires investigating in detail meta-organizations' efforts to improve their legitimacy. As such, it closely intertwines organizational and field processes. Following Yin (2013), the need to study a phenomenon that cannot be isolated from its context led us to choose a qualitative research design. More precisely, our research design is based on an indepth case study of a French national federation (Fédération Addiction) formed by the merger of two former professional CSOs in the field of addictions. Significantly, this federation consists mostly of organizational members and can be considered a specific kind of MO as such. The merger was intended to create a national network of professionals and to promote a new approach to addictions, as opposed to the prevailing division between alcoholism and drug abuse. The organization now brings together professionals in healthcare, education, prevention, support and harm reduction, focused on a cross-disciplinary approach to addictions.

The federation is a specific kind of $\mathrm{MO}$ in the sense that its members are both organizations (private and public) and individuals (healthcare professionals), whose roles and positions are distinct. It is also specific in the sense that it operates mainly with CSOs and is a civil society meta-organization. Our case echoes the case analyzed by Karlberg et al. (2015) in the field of women's defense (SWL). The organizations devoted to women's defense pursue a diversity of missions according to different issues (prostitution, abortion, violence) and positions (only some of the organizations adopt a strong feminist position); hence the issue of how to group all those organizations under one label of "women's defense." One difference between Fédération Addiction in our research and SWL in Karlberg's research is that the former has a strong professional dimension, whereas the latter operates more as a 
social movement. Still, beyond the diversity of its members and its civil society dimension, Fédération Addiction shares many similarities with the general missions and activities of MOs as depicted in the literature: producing information, defining a collective expertise, acting as a representative for their members, etc. (Ahrne and Brunsson, 2008). It also benefits from strong power of negotiation with governmental bodies. In that sense, we argue that our case is emblematic of those organizational fields where many actors of different types (for and non profit, individuals, organizations and meta-organizations) interact in order to coproduce public policies in a democratic way.

In order to gain knowledge of the history of the field of addictions and its key actors, we carried out an initial series of four exploratory and unstructured interviews with members of the current federation and the main organizations of the field. Previous academic works developed in history and in political science were also exploited in order to better understand how the public policy shift in favor of the addiction approach occurred. A chronology focused on field processes was built and is developed in more detail later in the paper (see figure 1).

Our method of data collection was based on the questioning of 32 different actors through 38 semi-structured interviews. The sampling structure is presented in table 1 .

\begin{tabular}{|c|c|c|}
\hline & Characteristics of the interviewees & Number of interviews \\
\hline \multirow{5}{*}{ 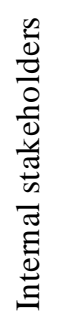 } & Chairman & 1 \\
\hline & Managers & 5 \\
\hline & Directors & 8 \\
\hline & Employees & 7 \\
\hline & Former chairmen of F3A and ANITEA & 2 \\
\hline \multirow{3}{*}{ 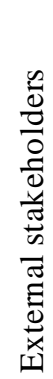 } & $\begin{array}{l}\text { Policy officers in Regional health authorities } \\
\qquad \text { (4 distinct authorities) }\end{array}$ & 6 \\
\hline & $\begin{array}{l}\text { Policy officers in the Governmental committee against drugs } \\
\text { and addictions }\end{array}$ & 2 \\
\hline & Directors of other CSOs in the field & 7 \\
\hline - & & 38 \\
\hline
\end{tabular}

Table 1: Sample of respondents

All interviews have been recorded and then transcribed. They consisted of a standardized introduction and a set of core questions. Interviews with members of the 
federation focused on the merger proceedings between F3A and ANITEA. Respondents were asked about the history of the field and the organizations involved in the merger, the evolution of the merger talks and processes, the role of key actors, the perceived obstacles to merger and how they were resolved, and the outcomes of the merger, anticipated or not, in terms of internal structuring and external advocacy. Because of the characteristics of the data collection process, some interviews relied on retrospective questions, especially when respondents were asked to describe former federations and the pre-merger processes. To avoid the risks of studying a past phenomenon, memory lapses and a posteriori rationalization from respondents, a number of questions contextualized the merger processes, and secondary data linked to the merger proceedings were simultaneously collected and analyzed (Miles and Huberman 2003).

Two kinds of external stakeholders were interviewed. On the one hand, policy officers in public agencies at a national (Governmental Committee against drugs and addictions) and regional level (Regional health agencies) were asked about their perception of the structuring process of the new federation, as well as about its current role in the field in general and through concrete examples. Members from other organizations of the field - some who were involved in the new federation, some who did not - were also interviewed. They were first asked to describe their organization, the evolution of the field and the federative processes at stake. They were finally asked about the role of Federation Addiction in terms of representation of professionals in the field, and in terms of contributions to professional practices.

A documentary analysis was also carried out in a triangulation perspective, based on different internal sources from Fédération Addiction (status, project, annual reports, minutes of general assembly, diverse workshops' and meetings' minutes). Finally, as non-participants we attended regional seminars, a general assembly, and the annual congress of the Fédération Addiction. Data from the interviews, documents and notes were aggregated, coded, and analyzed using analytic description (Strauss and Corbin 1998).

Our analysis focused on the meta-organizations' restructuring following the emergence of the field of addictions. The analysis first relied on processual analysis (Langley, 1999). A narrative strategy was adopted in order to describe meta-organizing processes over the last decade, and to compare it to the field events that were identified in the exploratory phase of our work. Different stages could be identified and organized through visual mapping (see figure 2). The different phases were compared to categories that emerged from the 
literature dealing with meta-organizations and legitimacy: governance, internal structuring, categorization in the field.

\section{The case study: the emergence of a new Federation in the field of addiction}

\section{A fragmented field following the public policy shift}

Following the public reforms implemented between 2002 and 2008, all existing centers adopted the new status of CSAPA and formally abandoned their specialized activities. However, their practices often remained specialized, largely due to local specificities and the policies of the regional health authorities in charge of structuring the health care offer.

\footnotetext{
"There have been very different ways of interpreting and enforcing the law of 2002 and the following decree of 2008 at the local level. Some regional health authorities considered that pre-existing centers would have to merge to deal with any kind of addictive behavior, whereas in other regions they simply asked them to adopt the new CSAPA status without having to restructure their activities." (Director of a national association)
}

In parallel, professional practices remained highly divided. Alcoholism professionals - mostly doctors - had been characterized by medical logic and a "care approach," according to which alcoholism could and should be cured, the paramount goal for these practitioners being achieving abstinence (Bergeron 2001). On the other hand, professionals dealing with illicit drugs had traditionally been characterized in the public sphere as having a militant logic and political focus, since they considered the legal regime for drugs excessively repressive (possession as well as simple use qualified as criminal offenses in France). These actors were also very active during the HIV epidemic in the 1980s and 1990s, when they felt the need to implement a harm reduction approach, accompanying drug users in order to reduce physical harm rather than promoting abstinence, and to advocate the recognition of patients' rights. So the new field of addictology was characterized by strong divisions.

\footnotetext{
"We were involved in a social approach to drug use and we were opposed to the idea that this issue should be 'medicalized.' The way we were organized as well as our cultural background did not make it possible to work with medical professionals and doctors." (A former member of ANITEA, Association Nationale des Intervenants en Toxicomanie et Addictologie)
}

There was no solution to these divisions in the legal reforms that were implemented. The law of 2002 had a strong impact on operators (local organizations and centers dealing 
with addictive behaviors). However, the reform did not address the issue of professional practices and the common grounds on which all the professionals involved in the new field of addictions would now have to rely on, despite the extreme differences that characterized the former fields of alcohol abuse and the use of illicit drugs.

\section{The federative level}

Two national federations used to share the field in the earlier structure of the sector. The F3A (Fédération des Acteurs de l'Acoologie et de l'Addictologie) brought together professionals involved in the treatment and prevention of alcoholism, while ANITEA represented practitioners dealing with people using illicit drugs. The F3A had initially been created to promote an approach to alcoholism based on the need to improve the quality of life of consumers, reducing suffering and raising awareness of the risks linked to consumption. Historically, this association relied on a majority of small organizations and medical teams working in hospitals or private centers and looking for public recognition. Only one national organization, ANPAA (Association Nationale de Prévention en Alcoologie et Addictologie), figured among its members. On the other hand, ANITEA was founded by professionals who were also activists, defending a comprehensive approach to drug addiction in public policy. It primarily involved social workers, psychologists and educators, and it was therefore characterized by strong opposition to a purely medical approach to drug addiction. Both federations favored an enlarged approach to addiction issues and the need to abandon a segmented approach based on substances (alcohol, drugs or tobacco). Table 1 shows the main differences between the two organizations.

\begin{tabular}{|c|c|c|c|}
\hline & & F3A & ANITEA \\
\hline \multicolumn{2}{|l|}{ Number of members } & 382 & 360 \\
\hline \multirow[t]{2}{*}{ Types of members } & Individual members & $212(55.5 \%)$ & $291(80.8 \%)$ \\
\hline & Legal entities & $\begin{array}{c}170(44.5 \%) \\
\text { Mostly hospital centers for } \\
\text { alcoholism }\end{array}$ & $\begin{array}{l}69(19.2 \%) \\
\begin{array}{c}\text { Mostly local centers for drug } \\
\text { addiction }\end{array}\end{array}$ \\
\hline \multirow[t]{2}{*}{ Resources } & Public funding ${ }^{1}$ & $85 \%$ & $40 \%$ \\
\hline & Private resources ${ }^{2}$ & $15 \%$ & $60 \%$ \\
\hline
\end{tabular}

Table 1. Characteristics of the F3A and ANITEA

\footnotetext{
${ }^{1}$ Subsidies and public orders.

${ }^{2}$ Subscriptions, donations and sponsorships.
} 
When addictology finally gained public recognition at the turn of the millennium within a new regulatory framework, both of these federations changed their goals and names to rally practitioners from all sides of addictology (see Table 2).

\begin{tabular}{|l|l|}
\hline F3A & $\begin{array}{l}\text { "Promote a field of care for addictions, involving multidisciplinary teams from all } \\
\text { sectors and professions; establish the place of those teams in public health and social } \\
\text { plans; bring together addiction protagonists; carry out research to enable addiction } \\
\text { workers in the field to contribute to public policies." }\end{array}$ \\
\hline ANITEA & $\begin{array}{l}\text { "Be an intermediary for meetings, exchanges and views of stakeholders in the field of } \\
\text { drug addiction and other addictive behavior; represent stakeholders and specialized } \\
\text { structures in various public and private bodies; promote the needs and problems faced } \\
\text { by the sy stem of care addiction and prevention, both in terms of material resources, } \\
\text { organization, and principles for action; ensure the recognition of users of psychoactive } \\
\text { substances as individuals and as citizens in care and prevention practices, as well as in } \\
\text { decision-making bodies; defend the view that psy choactive substance use cannot be } \\
\text { isolated from the social, cultural and economic context in which it occurs; promote a } \\
\text { preventive, clinical and therapeutic approach to drugs and addiction, taking into } \\
\text { account their psy chological, social and biological dimensions; provide the means to } \\
\text { achieve these goals [...]; to assist and defend individuals and legal entities who are } \\
\text { victims of offenses in connection with their missions in the field of addictions; to } \\
\text { intervene in defense of the collective interests of its members within the framework of } \\
\text { its statutory purpose." }\end{array}$ \\
\hline
\end{tabular}

\section{Table 2. F3A and ANITEA: goals}

However, because of the major changes in the field, the coexistence of the two federations was quickly questioned and their legitimacy was threatened. Both appeared unable to continue federating and representing addiction actors at the national level. Within ANITEA, people had the feeling that a crisis was occurring, and that the organization "began to falter" (ANITEA's President). Governance was tightening to a restricted team within the board that was not only small but also suffered from a lack of diversity. At the same time, the number of ANITEA members was on a downward trend.

As far as F3A was concerned, compared to ANITEA, it was weaker in terms of funding and structuring, and less active in the public sphere. As a consequence, it was obvious that it would not be able to survive in the new context (legal reform and a global approach to addiction). Another weakness was that each of the two federations failed to present as the relevant and representative correspondent for addiction issues. Although professionals like addiction physicians, social workers, and psychologists had created both associations, there were no teachers, family physicians, or pharmacists - all very concerned by the topic - among the members. Neither was there space for patients and beneficiaries; there was awareness of the need to involve them but no way had been found to do so. Finally, the segmentation of addiction actors in the field inhibited any useful debates with public authorities, and hindered the possibility of advocacy and the transformation of public policy. The national public 
authorities expected to open dialogue with a single federation that could offer higher level of legitimacy. In this context, the governance bodies in both federations quickly came to an agreement and in the early 2000 s decided to merge. The merger took place in a context of strong political changes nationally and big challenges for both organizations. As a result, the merger became a legitimation strategy, adapting to the profound legal reform that had disrupted the whole field. However, it took several years for the boards of both federations to take the actual decision to merge, following deep reflection about the nature of the new entity and how it could be structured.

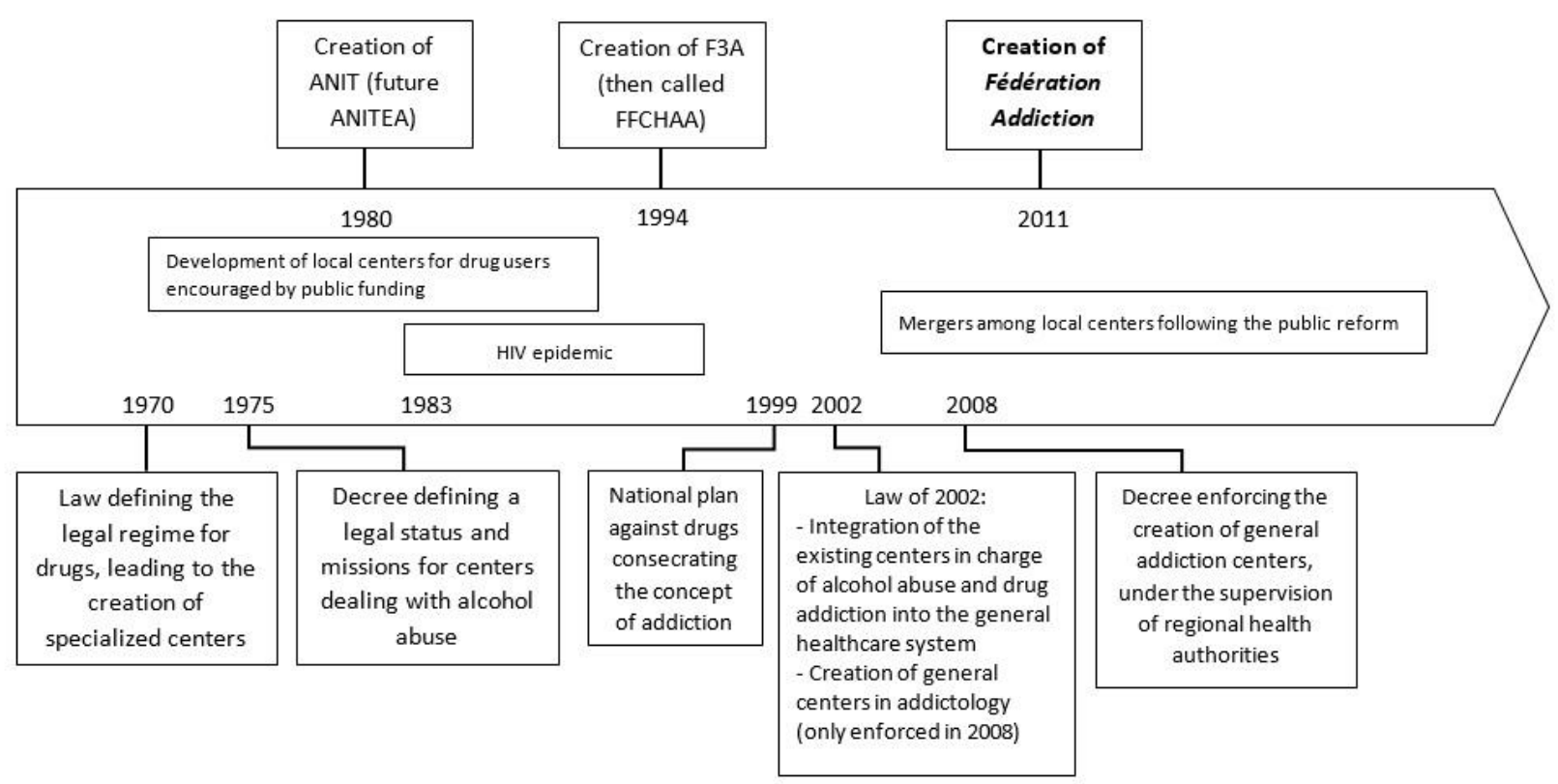

Figure 1: The addiction field in France: a chronological view

\section{The creation of a new meta-organization to rally professionals in the field}

The decision to merge followed a profound legal reform that disrupted the whole field. As a result, there was a need to adapt to the new framework defining public action.

From 2008, regular meetings between members of the two boards were organized to think about the missions of the future unified federation. The stated goal that emerged from these reflections was to create a network that would help all the professional practitioners who assist beneficiaries, taking an interdisciplinary approach simultaneously embracing medical, psychological, and social perspectives. To this end, the statutes of the new federation expressed the wish to create a collective expertise that would be both a common product and at the disposal of all federation members. This goal of creating a common expertise 
encompassing the alcoholism and drug addiction fields was asserted in a context where the evolving regulatory framework had recently established the creation of universal centers to replace specialized structures. But, at the same time, public authorities had put little emphasis on the necessary evolution of professional practices implied by this shift. Thus the collective expertise promoted was also intended to help devise public policy.

\begin{abstract}
"We had to show in some way that there was no opposition between social, medical, and hospital practitioners. To do so, the best thing was to ally with others whose history was the exact opposite of ours. Unlike us, they were highly medicalized and together we had the conviction that this overall knowledge would make us actors able to deal with the issue of addictions in its entirety." (A former director of ANITEA)
\end{abstract}

From a public policy perspective, as noted earlier, the federation now promotes a comprehensive approach to addictions encompassing medical, psychological, and social perspectives. This involves two major and specific goals. The first is to oppose a strictly repressive stance, in particular by pleading for the decriminalization of drug consumption. The second is to oppose a strictly medical approach, according to which addiction is considered a disease for which the only solution is abstinence.

\title{
Intertwined, internal and external, legitimating processes
}

\section{Democratizing organizational processes}

The decision to merge involved a profound reflection on the moral grounds of the new entity. Although an agreement was quickly reached over the principle of the merger, its effective implementation was achieved only after several years. In the steps toward a merger that followed the agreement, organizational design was characterized by the implementation of participatory and democratic internal processes to bring together a diversity of stakeholders involved in addiction issues. Until then, the public positions of both ANITEA and F3A, especially those directed toward public authorities or the general public, were stated by a few board members who were high-profile experts in the field. Ordinary members had no direct say in the associations.

\footnotetext{
"There was the expertise of long-term members, leading figures who were famous and respected. When they gave advice, everyone listened. [...] And then those figures co-opted other people who were competent in this or that subject."( The current chairman of the Fédération Addiction)

"Our association was looking inward. There were fascinating people. Among the 30 directors, a lot were involved in research and were writing books. But those 30 experts were taking decisions for the whole network, they were in all the governance bodies and in working committees. They were doing a lot. So there was a lot of knowledge and intelligence but the system was closed, very closed." (The current manager of the Fédération Addiction)
} 
Conversely, the new organizational status firmly stated the wish to develop a collective expertise emanating from the practical experiences of all members. This new participatory approach was initiated in 2009 and led to the redefinition of the respective roles of expert board members and field practitioners to promote "a collective expertise rather than a collective of experts" (a director of Fédération Addiction). It was implemented through several specific and practical projects, mostly the production of reference documents taking an inventory of good practices emerging from the field. These reference documents are intended for both members and public authorities. The production of these reference documents, which can be considered collectively formulated bodies of knowledge, are carried out through working groups. Each working group includes about 15 members closely related to the topic, meeting about four times a year. They are steered by a duo consisting of a board member related to the topic and a project manager working for the federation and specifically in charge of organizing the group's work. Moreover, these groups are now open to a wider range of stakeholders. They do not consist only of professional practitioners specialized in the field (doctors in addictions, social workers, psychologists); they also include general practitioners, teachers, and even beneficiaries.

\footnotetext{
"Fédération Addiction does not have much in common with the former ANITEA or F3A. It has been completely transfigured because of the merger. They have kept the expertise and added a strong dialogue with field members through a participative approach. Even the contributions to international debates are now submitted to a part of the membership. From a small committee of experts it has become something much more representative." (A regional representative of the federation)

"Our legitimacy does not arise from scientific knowledge; rather, it comes from the strength of our network, which is now very significant." (A federation employee)
}

\section{Reconfiguring governance bodies}

There was a similar move where governance bodies are concerned. In compliance with the new general orientation, rules about representation on the board were modified. At the initial stage, former board members of ANITEA and F3A were represented equally in the board of the new federation. Three board colleges were set up to represent legal entities, individuals and regional representatives in the federation.

Reconfiguring governance bodies was also the occasion to rally categories of professionals involved in addictions who had not previously been represented in the F3A and ANITEA. Both these federations relied on particular categories of stakeholders who had contributed to shaping their field (specialists in alcohology on the one hand, professionals working in local drug addiction centers on the other). The general assembly of the Fédération 
Addiction voted in favor of integrating general practitioners in a special committee attached to the board of directors. This special committee relies on a pre-existing network of general practitioners particularly involved in addiction issues. The committee was intended to enable these professionals to discuss specific aspects of addictions they had to deal with in their practice. The committee now has an autonomous voice in the federation and has been recognized by public authorities as a contributor to debates and public hearings about the legal framework for addictions. For instance, following the committee's claims, general practitioners have recently been granted the right to deliver substitution treatments, previously reserved to the centers specializing in addictions (CSAPA).

At the same time, in accordance with the reshaping of the public policy, which had adopted a regional approach by establishing regional health authorities in 2010, the new federation strengthened its internal regional structuring. It was decided that, from now on, regional representatives would be elected by federation members. Moreover, the regional representatives were to be granted an ex officio status as federation board members. Their role is to animate networks of regional members, by relaying the federation's work downward and developing collective work on specific topics at a regional level. The goal is to act as a common interlocutor addressing regional health authorities about health care provision at a local level.

\section{Stakeholders' involvement and legitimation of the federation}

The general orientations and new organizational schemes initiated before and during the merger process have led to the involvement of a wide range of stakeholders. By democratizing internal processes toward internal stakeholders and representing addiction professionals to external stakeholders and public authorities, the Fédération Addiction managed to align the interests of very different types of members of from different geographical areas.

\footnotetext{
"During debates at the national level we really needed a collective representative and not only individual 'stars.' We are now well-known and we are consulted in every public debate in the field of addictions. It is also very pragmatic because we play a role in improving professional practices. There are many activities, way more than before the merger. There is now a strong organization, with a high level of technical knowledge. We try to combine our activist values with this knowledge in our written arguments, which are then useful for public debates. Achieving such a balance is not easy." (A director of Fédération Addiction )
}

The Fédération Addiction is now a recognized representative of stakeholders involved in addiction issues. First, the number of members, especially active members, has increased 
dramatically, through its involvement in national representation, participatory working methods, and regional structuring, Interviews carried out with external stakeholders, especially public partners, show that the federation now contributes to the evolution of public policies in the field of addictions because of its highly visible role as a representative. These contributions are based on representation at public consultations set up before the law reforms, as well as informal actions at national and regional levels.

\footnotetext{
"It sparked strong rallying among actors in the whole field. Bit by bit we managed to define more and more complex goals. The last consisted in intervening in parliamentary debates about the planned reform of the health sector." (The chairman of Fédération Addiction )
}

The integration of diverse professionals, from both the former fields of alcohol and drugs, as well as new kinds of stakeholders, enabled the federation to define common principles of action and to tackle new dimensions of addictology; for example it has developed a national program linking addiction recovery with work insertion, and produced professional guides to issues such as the specificities of addictions among women, and new kinds of substance-free addictive behavior, like video games.

However, the coexistence of very different members, in terms of history, size, and professional ethics, remains a major difficulty for the federation. The merged organization managed to involve the vast majority of members from ANITEA but not all those working with alcohol dependency and the F3A. The ANPAA, the oldest and largest protagonist in the field, did not join the new federation. In interviews, several reasons for this refusal were given. The ANPAA claims strong legitimacy because of its long history (it was created at the end of the $19^{\text {th }}$ century as a part of the health movement) and the role it has played in leading action against the alcohol lobby. At a local level, there are troubled relationships between members who sometimes find themselves competing for restricted funding from public authorities. As a consequence, the ANPAA has helped revive another federation, the Fédération Française d'Addictologie. This MO used to be a simple forum for reflection and debate for addiction professionals and academics; it now aims to become an active federation by rallying the diverse actors who are reluctant to support the role the new Fédération Addiction now plays in the field of addictions. 


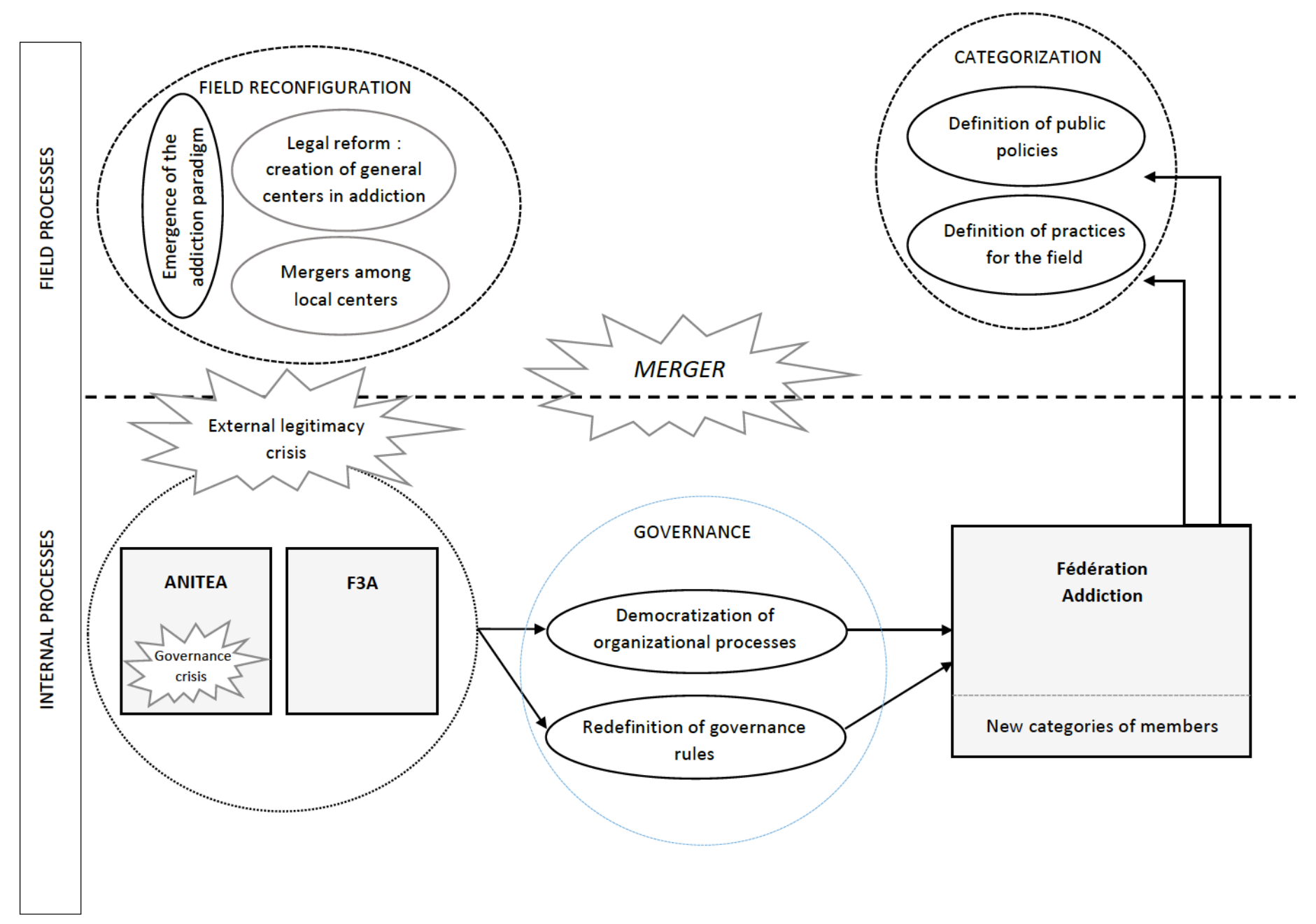

Figure 2: Internal and external legitimating processes of Civil Society Meta-Organizations in the addiction field 


\section{Discussion}

In this paper, we aim to analyze the external and internal legitimating processes in a civil society context where MOs play a significant role. We draw from an in-depth case study of two French federations in the field of addictions. We show how these two federations, theorized as Civil Society MOs (CSMOs), progressively built their legitimacy in a fragmented field, how they responded to a shift in public policy, and how they finally decided to merge, creating a new and bigger MO. Following the processes highlighted in Figure 2, we first organize the discussion of our findings around sets of questions: the first relates to the understanding of the dynamics and categorization processes within a field, thus illustrating external legitimating processes; the second relates to the dynamics of MOs themselves, thus illustrating internal legitimating processes. We then extend the analysis in the light of some most recent developments in MO literature relating to "co-evolution" of MOs and organizational fields and to the theorization function that underpins both the inward and outward functions of MOs. We finally add to the discussion a reflection about the definition of what makes a (CS)MO successful or "strong".

\section{Field dynamics and the role of MOs in the categorization processes}

Field theorists have long debated about how and why fields emerge, remain stable or change or about how and why fields boundaries are (re-)defined (Fligstein, 2013; Kluttz \& Fligstein, 2016). Our case study explains how public authorities trigger significant transformations in the field, but also how actors MOs take an active part in the categorization process. According to Hardy and Maguire (2010), an organizational field is characterized by three main components: actors' positions, which may be evolving in relation (or in response) to institutional changes; understanding or systems of meanings, that is, cultural expectations, shared cognitions, and beliefs (Zilber 2008); and formal rules, such as laws, professional standards, or norms. The importance and the specific features of those three components vary, depending on the status of the field (mature, emergent, fragmented). In our case, in France in the early 2000 s, addictology had the potentiality to become an organizational field, structured around different actors (two major federations, professional organizations, and individuals involved in the treatment of alcoholism and drug addiction), who had distinct understandings of how to manage addiction, different professional standards, and were bound by formal rules of governmental health policies. Di Maggio and Powell (1983) state that the presence of MOs signals the existence of strong interactions between organizations and their awareness of 
belonging to same field. The addictology field rests on two former fields: the care of alcoholics and drug addicts. As such, it has been divided between those who advocate a medical logic and care approach (mainly toward alcoholism), and those who advocate a militant logic and a social and psychological approach (mainly professionals in drug addiction). The field could be described as "fragmented" when it emerged as a result of the public policy shift in 1999-2002 and the creation of centers devoted to addictive behaviors in general, with no distinction between types or sources of addictions.

This public policy shift triggered a drastic change in the categories that had prevailed in the field until then, and for which MOs had been created: F3A represents a medical approach to the treatment of alcoholism, while ANITEA took a more psycho-social approach to drug addiction. Dumez (2008) outlines the role of MOs in the categorization process of a field. He considers that MOs are created when a set of organizations with similar identities decide to share information and actions to better confront their environment and to be represented by a supposedly more powerful organization. Dumez (2008) and Brankovic (2018) also argue that categorization is reinforced by the creation of MOs. From an individual organization point of view, Brankovic (2018) notes that joining or establishing a metaorganization can be seen as a self-categorization process, whereby the organization* membership in identity categories or groups are declared. But in the empirical literature devoted to MOs there is little mention of how categories emerge and are accepted, nor about the actors and factors that play a central role in that process. Karlberg's (2015) research is a good example, in the Swedish context, of the impact of both Europeanization and the Swedish government on the creation and legitimization of an MO in the women's defense movement, the Swedish Women Lobby. More generally, in her study on university associations, Brankovic (2018) stresses the fact that, not only organizations may join or establish metaorganizations in order to claim or reinforce an identity, but when meta-organizations are established by third parties (e.g. the state, international organizations or the law), the categorization and the identity of the meta-organization are also externally assigned and members are then expected to subscribe to it in order to secure or maintain legitimacy. In our case, the two existing categories (alcoholism and drug addiction) were dramatically challenged by the public reform, and the legitimacy of the two main respective federations or MOs was questioned, inviting or inciting them to merge, and represent the new category of "addictology." This mirrors the active role the government took in the health and social activities in France at the time. At a more general level, our case also exemplifies the two 
types of fields' changes defined in the Strategic Actor Field theory: "continuous piecemeal change" (conflicts between actors jockeying for positions) and "revolutionary change" (usually coming from outside, namely the public law in our case) (Fligstein, 2001, 2013; Fligstein and McAdam, 2011). In that respect, the two MOs, ANITEA and F3A, seek to solidify their power and position through the merger.

\section{The merger unveils intertwined legitimating processes}

The academic literature about MOs stresses the fact that they usually remain stable, even in cases of drastic change in their field (König, Schulte and Enders 2012) and barely adapt to institutional changes or crises. Besides, when there is an MO in a field, the "institutional zone" is fixed (Hardy and Maguire 2010). This is explained by the intrinsic culture of consensus and an elitist identity that characterizes MOs' ways of functioning (König et al. 2012; Dumez 2008), and by their durability even when new MOs are created, since their costs remain relatively low and their institutions relatively inert (Berkowitz and Dumez, 2016, p. 5). In our case, MOs actively react to the change of categories and decide to merge into one unique MO, Fédération Addiction. Several hypotheses may be suggested to explain this. First, the change was prompted by the French government, a legitimate thirdparty player in the field, and had probably been initiated before in one way or another by other institutional actors (health professionals, for example). In other words, an endogenous movement, combined with an exogenous decision, jolted the actors out of their inertia. Second, health is an ultimate common good for all actors, and it might be that, in civil society organizations, the willingness to pursue common goods is stronger than the tendency to remain unchanged. However, a kind of cultural inertia can be observed among some professionals in the addictology field, since the oldest physicians expressed their reluctance about the ongoing change.

The new categorization of the field is driven and strengthened by the new federation, and the merger may thus be understood as a means to accelerate the categorizing as well as the legitimating process. The merger appears as a matter of debates in many events and conferences organized by the federations. Through these events, the merger has a structuring and configuring effect on the field (Meyer et al., 2005; Zilber, 2011). It gives individuals the opportunity to "transform contested arguments into legitimated outcomes" (Lampel and Meyer, 2008 p. 1029; McInerney, 2008). A slow but strong transformative process is therefore progressively entailed on the ground. A new legitimate doctrine is elaborated thanks to the implementation of a democratizing process. This process is all the more crucial given 
the contrasting power of the two federations involved in the merger, which could have led the stronger to absorb the weaker, denting the legitimacy of the MO. In the context of the merger, the legitimacy dimension was critical given that the new federation had the ambition to exert influence over public policies related to addiction. This fact points to the intrinsically political nature of the Fédération Addiction. From this point of view, some interesting insights may be gained from Bonfils's (2011) study, which focuses on a disability MO in Denmark that is playing an increasing role in policy-making. By studying the way the Disabled People's Organizations Denmark (DPOD) has managed to unify the disability movement and maneuver itself into a unique position of political power, Bonfils illustrates the strategies of a MO adapting to government structures and new forms of governance. The DPOD MO has many similarities with the Fédération Addiction. Both MOs strive to participate in policymaking, to impose themselves as the key legitimate representative of different groups of stakeholders in the field when it comes to discussion with public authorities, and, to reach these goals, both have devoted much effort to involving a wide range of stakeholders through a participatory approach. One main difference, however, is that the Fédération Addiction has not yet fully succeeded in establishing a consensual approach to addictions, and bringing together all the relevant actors in the field: one important organization, ANPAA, which originates from the field of alcoholism treatment, is still refusing to adhere to the new federation.

\section{Co-evolution and the theorization function of MOs}

Our case study illustrates the fact that MOs are affected by the evolutions in the field at the same time that they are in a position to channel or even initiate these evolutions. This dual, interacting relationship, may be theoretically accounted for with the concept of coevolution developed by Rodrigues and Child (2003) and introduced in the MO literature by Cropper and Bor (2018). Cropper and Bor's contribution is of peculiar interest for our own research as they analyse the dynamics of MOs in a specific healthcare-related organizational field (i.e., pediatric cares in UK). They refer to the co-evolution concept to highlight the fact that the environment influences the MO, but, at the same time, the MO influences the environment, an argument that has also been recently developed by Mountford and Geiger (2018),.In our case, the co-evolution concept seems relevant with regard to the way the addiction approach emerged and became dominant in the 1990's, paving the way to the legal changes that led to the reconfiguration of the field at the turn of the century. This new approach, initially elaborated by neurologists and psychiatrist in the course of the 1990's, 
became rapidly accepted by many professionals in France and spread out both within the alcohol and the drug addiction fields, with no or few observable resistance among the organizations acting in these fields. It may also explain why ANITEA and the F3A decided to merge as early as in the first years of the new century. The long stretch of time between the law (2002) and the official merger (2011) was essentially due to discussions about the governance of the future federation and to a desire to carry out an extensive participative process which would ensure the involvement of all the stakeholders, and a central position of the merged federation in the newly expanded organizational field.

The way the addiction approach became dominant and influenced public policy in France illustrates how theorization practices in a field may contribute to the categorization process within it, and thereby indirectly contribute to shape the configuration of organizational fields. Theorization is often a crucial ongoing practice influencing actors' behavior in a given field, and this notion is particularly relevant when it comes to understand the role of MOs in their organizational fields and how they can influence both public policy and the practices of their members: in our case, the aim to create a collective expertise that would be both a common product and at the disposal of all the federation's members, is explicitly expressed in the statutes of the Fédération addiction.

From a MO perspective, the theorization process interacts both with the inward and outward functions of MOs. In complement to the three general purposes presented by Arhne and Brunsson (2008), i.e. 1) interaction among members, 2) collective action among members and 3) creation of collective identity, Berkowitz (2016) highlights the information production function of meta-organizations to support each of these purposes. In this regard, the collective expertise production mission of the Fédération addiction and the way it is implemented also be illustrate the transversal dimension of the theorization function of MOs. Producing public documents interacts with the MO's outward functions both directly - some of these documents may advocate for some changes in public policy -, but also indirectly as they contribute to strengthen the visibility and the credibility of the federation as a source of collective expertise and, consequently, its external legitimacy. But this theorization practice also interacts with the federation's inward functions since its explicit goal is to come in support of the actors from the field in their daily activities. Moreover, the consequences of this collective expertise production mission must not only be considered with regard to its immediate "output" (i.e. the documents published) but also with regard to the overall process that gives rise to them. The participative and multi-stakeholder approach that had led to their 
production was also an important tool in order to sustain the internal legitimacy of the newly created federation, along with the reconfiguration of the governance bodies.

Overall, this suggests that the MO literature has given a theoretical account of the theorization activity of MOs in two different - but not exclusive - ways. On the one hand, the theorization activity of MOs may be analytically considered as a MO function in its own right; on the other hand, in the same ways that inward and outward functions of MOs interact each other, the theorization function interacts with the other functions of MOs. Therefore, the theorization function of MOs may also be conceptualized as an instrumental practice, i.e. as a "mean", in support of other functions as much as it constitutes a "defining ouput" for many of these organizations which, by their very nature, try to influence the general perception in their fields about "how things have to be done".

\section{The paradox of weak and strong meta-organizations}

The idea that MOs vary in form and nature is widely supported in the literature, and several possible factors are suggested as explanations: the degree of differentiation among members, the dependence of members on their membership, the members' need to be regarded as independent organizations, the competition between organization and members, the motives for the establishing of the meta-organization, the number of members, the economic resources of the MO, and so on (Ahrne and Brunsson 2010). Fédération Addiction refers to the "multi-stakeholder" type of MO defined by Berkowitz and Dumez (2015), where the outreach strategy consists of extending the boundaries of the organization and integrating new members of different types (private, public, civil society organizations, etc.). König and al. (2012) for their part point out that it remains difficult to assess an MO's success or performance: is it a question of size, membership completeness, capacity of action, monopolistic position, profit, growth, etc.? Besides, the authors claim, "the performance criteria of an MO are not intertwined with those of external stakeholders", and "efficiency is not as important in MOs as in other organizations".

The governance of the new Fédération Addiction was reconfigured after the merger so as to be as representative as possible of the diverse stakeholders involved with the federation. Its ability to attract many individual professionals from the healthcare sector (specialized and general practitioners, hospital practitioners, social workers) undoubtedly contributes to its legitimacy. Yet, to what extent are the specific characteristics of Fédération Addiction (a civil society MO, encompassing very diverse members) beneficial or detrimental to its different 
missions? Arhne and Brunsson (2010) assume that "MOs where the members are highly differentiated will be weaker than others," but that "the higher dependence of the members on the MOs for their operations, the stronger will be the MO." Analysing international governmental organizations conceived through the MO theory, Arhne, Brunsson and Kerwer (2016) explain both their weaknesses (internal tensions, inefficient decision making process, reluctance to reform themselves) and their strengths (easy to establish, expansive dynamic).

Our case study highlights a paradoxical situation, where the MO's members are highly differentiated and weakly dependent on the MO for their action, but where the MO succeeds in fulfilling its missions, at least partially. Besides, ANPAA's choice not to join the MO mirrors some underlying conflicts and political tensions in the field against any hegemonic position. The resulting situation is not only the coexistence of Fédération Addiction and ANPAA, but also the revival of a formerly almost dormant or "ghost" federation (Berkowitz and Bor, 2017), the FFA, who was initially funded by ANPPA and two other federations (one operating in the field of alcoholism, and the other operating in the field of tobacco addiction), whose members were mainly scholars and professionals invited to debate, and which now have been joined by several other organizations. Still, Arhne and Brunsson (2005) consider that "there is a strong tendency towards monopoly among these [meta]-organizations." In the Danish field of disability, Bonfils (2011) shows that, despite the high diversity of existing approaches, the legitimacy issue led to a monopolistic situation.

Several factors may be suggested to explain the decision of ANPAA not to join the new federation. ANPAA's size and power was probably critical enough to keep it from marginalization, considering that the organization had long led important actions in the field. ANPAA was the only member of the former F3A to have a national scope and a long history (created in 1872). At the same time, its integration in the new federation would probably have posed a threat on its own identity. The main point here is that ANPAA, while not being an MO itself, carries out some functions that are also typical of MO's: one of its explicit mission is to be represented in public debates and to promote professional exchanges. Significantly, this federation is a member of a European MO, Eurocare (The European Alcohol Policy Alliance), which regroups 60 organizations across 25 European countries, "involved in advocacy and research, as well as in the provision of information and training on alcohol issue". And ANPAA is historically linked to Eurocare since the European MO was created in 1990 following a congress organized by ANPAA in Strasbourg. Besides, the federation had changed its name as early as 2002 (from Alcohology to Alcohology \& Addictology). All this 
confirms one of the characteristics of MOs underlined by Berkowitz and Dumez (2016), namely the difficulty for an MO to be attractive to larger members that might see it as a competitor, especially when both entities present strong similarities with regard to their territorial scope and functions. By contrast, this also highlights that the fact that ANITEA and F3A agreed to dissolve themselves to form a new federation is a very singular event, explained and allowed by specific factors and strong evolutions in their environment, whereas the ANPAA decision not to join the Federation Addiction is more in line with what MO theorist traditionally argue about the potential conflicts and tensions between MOs and members presenting strong similarities.

Overall, this calls for a more precise definition of what is a "strong MO." Fédération Addiction is powerful when negotiating with public authorities, when producing expertise and information, and even when co-constructing public policies in its field, but it has not succeeded in establishing and holding a monopolistic situation and attracting all influential organizations in the field.

The decision of ANPAA not to join the Fédération Addiction nevertheless raises the issue of the possible future evolution of the meta-organizational landscape in the French addiction field. The key point is that ANPAA, while not being an MO itself, carries out some functions that are also typical of MO's. ANPAA may be viewed as a competitor of the Fédération Addiction when it comes to discuss with public authorities about some collective and sectoral issues. The MO literature has identified several kinds of structural "misfits" concerning the ability of MOs and public authorities to collectively engage in a coconstruction of public policy approach. These structural misfits often constitute a driver for change in the meta-organizational landscape. For example, in their study of the pediatric care field in UK, Cropper and Bor (2018) show how, following some changes in the government policy, a lack of geographical 'fit' appears between the structures and territories of the NHS commissioning (i.e. the government body with which actors in the field have to negotiate) and the MO investigated. A similar issue was observable in the Fédération Addiction case: the new federation strengthened its internal structuring in response to the reshaping of the public policy, which had adopted a regional approach by establishing regional health authorities in 2010. A second kind of structural misfit may appear when there is no legitimate MO in a position to discuss with public authorities and act as a representative for all the actors in the field. This situation has been brought to light by Berkowitz and Souchaud (2017) in their study of the crowfunding sector in France, which led them to introduce the concept of 
"organizational void". In the opposite way, a third kind of structural misfit may occur when several MOs concurrently strive to be acknowledged as the collective representative of actors in the field. The coexistence of the Fédération Addiction and ANPPA may be interpreted in this regard even though this coexistence does not seem to have led to a really problematic situation. Indeed, even if several public authorities interviewees have expressed some incomprehension about the decision of ANPPA not to join the Fédération Addiction, the different government bodies have until now agreed to engage with both entities. This state of affairs, nevertheless, may evolve. As noted earlier, several MO researchers have pointed out the fact that some MOs were created as a response to a public authority request. It will then be interesting to observe if a similar kind of influence will impact the meta-organizational dynamics in the field and induce changes concerning the positioning of ANPAA and the Fédération Addiction.

\section{Conclusion}

Our in-depth case study finally leads us to argue that "civil society MOs" (CSMOs) share some of the usual features of MOs depicted in the literature but also reveal some specific characteristics. We confirm the importance of stakeholders' representativeness in the governance of MOs and especially in multi-stakeholders CSMOs, and corroborate the general assertion that MOs closely relate to categorization-related issues and the categorization process itself in many ways: the legitimacy and the potential for action of MOs depend on the socially perceived appropriateness of the delimitation of the field that they claim to represent, and at the same time categorization is reinforced by the creation of MOs.. In doing so, we contribute to the current literature on MOs in two main ways. First, we show how a change in the relevant categorization may result from the dual and interacting actions of the MOs themselves and public authorities: on the one hand, MOs intend to produce information and a collective expertise that may sometimes affect the legitimacy of the current categories and field delimitations; on the other hand, policy-makers are in a position to modify the institutional context to which MOs have to adapt, especially if they want to keep their influence in the process of policy-making. Second, our case study illustrates how, while being a response to an external legitimacy crisis following the change of relevant categories, a restructuring of the MOs landscape may strengthen the salience of internal legitimacy issues federative actors are confronted with in order to maintain their representativeness and their centrality in the new expanded organizational field. In this dynamic context, external and 
internal legitimating processes appear closely intricate, and categorization and governance issues appear strongly interrelated.

Moreover, we contribute to the literature on organizational fields by looking into, with MO theoretical lenses, how a reconfiguration of fields may result from a change in the prevailing categories upon which they had been built. This change in the prevailing categories may result from exogenous events, such a drastic evolution in public policy, but also, sometimes concurrently, from the actors in the field, especially through their theorizing activities. Hence, a change in prevailing categories affects the cognitive legitimacy of the actors in the field, which in turn may drive them to make evolve their organizational identity and/or to collectively restructure, thereby reinforcing the legitimacy of the new prevailing categories and the reconfiguration of the fields. Finally, all this calls for a more detailed and explicit articulation between the theory of MOs, the organizational fields literature and research on categorization processes.

The main limitation of our case lies in the specificity of our research field embedded in the French context of CSOs. But, at the same time, we argue that such a specific context is emblematic of the current "network society", where close interactions do exist between CSOs, public institutions and private companies, and where public policies are co-produced (Bovaird, 2005) through democratic governance (Laville, Young \& Eynaud, 2016). Therefore, the perspectives opened by this study provide some stimulating avenues for research. The specificities of MOs operating as a civil society organization (CSMO) deserve researching on a theoretical level as well as an empirical level. Thus, the case of MOs whose members are both organizations and individuals needs better understanding, in terms of their organizational dimensions (decision-making, governance,...), their impact on action and negotiation, their ability to impose a unique voice in a field, their expertise and information production. Further research could contribute to the design of a more complete typology of MOs, in relation to their missions and efficiency, given the wide variety of forms encompassed by this kind of organization. The interaction of internal and external legitimating processes - which occurs in CSMOs - allow them to bridge the different components of the network society. By gathering actors who usually do not work together, they are able to look for common good. This ability of private organizations such as CSMOs to work for public interest is a chance for renewing the public action and for addressing global societal challenges. In this context, the study of the legitimating process of MOs working in the civil society field is particularly relevant. 


\section{References}

Ahrne, G., \& Brunsson, N. (2005). Organizations and meta-organizations. Scandinavian Journal of Management, 21(4), 429-449.

Ahrne, G., \& Brunsson, N. (2008). Meta-organizations. Edward Elgar Publishing.

Ahrne, G., \& Brunsson, N. (2011). Organization outside organizations: The significance of partial organization. Organization, 18(11), 83-104.

Ahrne, G., \& Brunsson, N. (2012). How much do meta-organizations affect their members?. In Weltorganisationen (pp. 57-70). VS Verlag für Sozialwissenschaften, Wiesbaden.

Ahrne, G., Brunsson, N., \& Kerwer, D. (2016). The paradox of organizing states: A metaorganization perspective on international organizations. Journal of International Organization Studies, 7(1), 5-24.

Ahrne, G., Brunsson, N., \& Seidl, D. (2016). Resurrecting organization by going beyond organizations. In Management Research (pp. 121-140). Routledge.

Ahrne, G., Brunsson, N., \& Seidl, D. (2017). On the fruitfulness of the concept of partial organization: A rejoinder to Apelt et al. European Management Journal, 35(3), 297-299.

Apelt, M., Besio, C., Corsi, G., von Groddeck, V., Grothe-Hammer, M., \& Tacke, V. (2017). Resurrecting organization without renouncing society: A response to Ahrne, Brunsson and Seidl. European Management Journal, 35(1), 8-14.

Bailey, D., \& Koney, K. M. (2000). Strategic alliances among health and human services organizations: From affiliations to consolidations, 41.

Bang, H., \& Esmark, A. (2009). Good governance in network society: Reconfiguring the political from politics to policy. Administrative Theory \& Praxis, 31(1), 7-37.

Bergeron, H. (2001). Dispositifs spécialisés "alcool" et "toxicomanie", santé publique et nouvelle politique des addictions. Paris: Observatoire français des drogues et des toxicomanies.

Berkowitz, H. (2016). Les méta-organisations rendent-elles performatif le développement durable? Stratégies collectives dans le secteur pétrolier (Doctoral dissertation, Université Paris-Saclay).

Berkowitz, H., \& Bor, S. (2017). Why Meta-Organizations Matter: A Response to Lawton et al. and Spillman. Journal of Management Inquiry, 1056492617712895.

Berkowitz, H., \& Dumez, H. (2015). La dynamique des dispositifs d'action collective entre firmes: Le cas des méta-organisations dans le secteur pétrolier. L'Année sociologique, 65(2), 333-356.

Berkowitz, H., \& Dumez, H. (2016). The Concept of Meta-Organization: Issues for Management Studies: The concept of meta-organization. European Management Review, 13(2), 149-156.

Berkowitz, H., \& Souchaud, A. (2017). Combler un vide organisationnel dans la fabrique d'une politique publique: l'émergence d'une méta-organisation. Politiques et Management public, 34(1-2), 43-60.

Boléat, M. (1996). Trade association strategy and management. London: Association of British Insurers.

Bolkeat, M. (2003). Managing trade associations. London: Trade Association Forum.

Bozeman, B. 1987. All Organizations are Public: Bridging Public and Private Organizational Theories. San Francisco: Jossey-Bass.

Bozeman, B., \& Bretschneider, S. (1994). The "publicness puzzle" in organization theory: A test of alternative explanations of differences between public and private organizations. Journal of public administration research and theory, 4(2), 197-224. 
Brankovic, J. (2018). How do meta-organizations affect extra-organizational boundaries? The case of university associations. In Towards Permeable Boundaries of Organizations? (Vol. 57).

Brès, L., Raufflet, E., \& Boghossian, J. (2018). Pluralism in organizations: Learning from unconventional forms of organizations. International Journal of Management Reviews, 20(2), 364-386.

Bonfils, I.S. (2011). Disability meta-organizations and policy-making under new forms of governance. Scandinavian Journal of Disability Research, 13(1), 37-51.

Bovaird, T. (2005). Public governance: balancing stakeholder power in a network society. International Review of Administrative Sciences, 71(2), 217-228.

Brown, L.D., (2008). Creating credibility. Legitimacy and accountability for transnational civil society, Kumarian Press, USA.

Cotton, E., \& Gumbrell-McCormick, R. (2012). Global Unions as imperfect multilateral organizations: An international relations perspective. Economic and Industrial Democracy, 33(4), 707-728.

Cropper, S., \& Bor, S. (2018). (Un) bounding the Meta-Organization: Co-Evolution and Compositional Dynamics of a Health Partnership. Administrative Sciences, 8(3), 42.

Deephouse, D. L., \& Suchman, M. (2008). Legitimacy in organizational institutionalism. In

The Sage handbook of organizational institutionalism (49), p. 77.

DiMaggio, P., \& Powell, W. W. (1983). The iron cage revisited: Collective rationality and institutional isomorphism in organizational fields. American Sociological Review, 48(2), 147-160.

Dougherty, D., \& Dunne, D. D. (2011). Organizing ecologies of complex innovation. Organization Science, 22(5), 1214-1223.

Dumez, H. (2008). Les méta-organisations. Le Libellio d'Aegis, 4(3), 31-36.

Ehlinger, S., Perret, V., \& Chabaud, D. (2015). Quelle gouvernance pour les réseaux territorialisés d'organisations?. Revue française de gestion, 41(253), 369-386.

Einarsson, T. (2012). Membership and organizational governance. Stockholm, Sweden: Stockholm School of Economics.

Evers A., Laville J. L., (2004). «Defining the third sector in Europe » in «The Third Sector in Europe », ads Evers, Laville, Edward Elgar, Cheltenham, UK

Fligstein, N. (2001). Social skill and the theory of fields. Sociological theory, 19(2), 105-125.

Fligstein, N. (2013). Understanding stability and change in fields. Research in Organizational Behavior, 33, 39-51.

Fligstein, N., \& McAdam, D. (2011). Toward a general theory of strategic action fields. Sociological theory, 29(1), 1-26.

Fortané, N. (2011). Genèse d'un problème public : les «addictions ». D’un concept médical à une catégorie d'action publique ou la transformation des drug policies contemporaines. Université Lyon 2.

Frandsen, F., \& Johansen, W. (2015). Organizations, stakeholders, and intermediaries: Towards a general theory. International Journal of Strategic Communication, 9(4), 253271.

Gadille, M., Tremblay, D. G., \& Vion, A. (2013). La méta-organisation territorialisée, moteur d'apprentissages collectifs. Revue Interventions économiques. Papers in Political Economy, (48).

Gulati, R., Puranam, P., \& Tushman, M. (2012). Meta-organization design: Rethinking design in interorganizational and community contexts. Strategic Management Journal, 33(6), 571586.

Haque, S. 2001. 'The Diminishing Publicness of Public Service under the Current Mode of Governance', Public Administration Review, 61, 1, 65-79. 
Hardy, C., \& Maguire, S. (2010). Discourse, field-configuring events, and change in organizations and institutional fields: Narratives of DDT and the Stockholm Convention. Academy of Management Journal, 53(6), 1365-1392.

Johnson, C. (2004). Legitimacy processes in organizations. In Legitimacy Processes in Organizations (Vol. 22, p. 1-24). Emerald Group Publishing Limited.

Karlberg, E., \& Jacobsson, K. (2015). A Meta-organizational Perspective on the Europeanization of Civil Society: The Case of the Swedish Women's Lobby. Voluntas: International Journal of Voluntary and Nonprofit Organizations, 26(4), 1438-1459.

Kerwer, D. (2013). International organizations as meta-organizations: The case of the European Union. Journal of international organizations studies, 4(2), 40-53.

Kluttz, D.N., \& Fligstein, N. (2016). Varieties of sociological field theory. In Handbook of contemporary sociological theory, (pp. 185-204). Springer, Cham.

König, A., Schulte, M., \& Enders, A. (2012). Inertia in response to non-paradigmatic change: The case of meta-organizations. Research Policy, 41(8), 1325-1343.

Langley, A. (1999). Strategies for theorizing from process data. Academy of Management review, 24(4), 691-710.

Laville, J.L., Young, D., Eynaud, P. (2015). Civil society, The Third Sector, Social Enterprise: Governance and Democracy, Routledge Publisher, Oxfordshire, April, paperback.

Lawton, T. C., Rajwani, T., \& Minto, A. (2018). Why trade associations matter: Exploring function, meaning, and influence. Journal of Management Inquiry, 27(1), 5-9.

Meyer, M., Buber, R., Aghamanoukjan A., (2013), In Search of Legitimacy: Managerialism and Legitimation in Civil Society Organizations, Voluntas, 24:167-193

Miles, M. B., \& Huberman, A. M. (2003). Analyse des données qualitatives. De Boeck Supérieur.

Mountford, N., \& Geiger, S. (2018). Duos and Duels in Field Evolution: How Governments and Interorganizational Networks Relate. Organization Studies, 0170840618789210.

Pallas, C. L., Gethings, D., Harris, M. (2015). Do the Right Thing: The Impact of INGO Legitimacy Standards on Stakeholder Input, Voluntas, 26:1261-1287

Pfeffer, J., \& Salancik, G. R. (1978). The external control of organizations: A resource dependence approach. NY: Harper and Row Publishers.

Powell, W. and R. Friedkin. (1987). "Organizational change in nonprofit organizations." In W. Powell (ed.). The Nonprofit Sector. New Haven: Yale University Press

Radnejad, A. B., Vredenburg, H., \& Woiceshyn, J. (2017). Meta-organizing for open innovation under environmental and social pressures in the oil industry. Technovation, 66, $14-27$.

Rajwani, T., Lawton, T., \& Phillips, N. (2015). The "Voice of Industry": Why management researchers should pay more attention to trade associations. Strategic Organization, 13(3), 224-232.

Rainey, H. G., \& Bozeman, B. (2000). Comparing public and private organizations: Empirical research and the power of the a priori. Journal of public administration research and theory, 10(2), 447-470.

Rodrigues, S., \& Child, J. (2003). Co-evolution in an institutionalized environment. Journal of Management Studies, 40(8), 2137-2162.

Scott, W. R. (1977). Effectiveness of organizational effectiveness studies, in P. S. Goodman \& J. M. Pennings (Eds.), New perspectives on organizational effectiveness: 63-95, SanFrancisco: Jossey-Bass.

Scott, W. R., \& Meyer, J. W. (1991). The organization of societal sectors. In W. W. Powell \& P. J. DiMaggio (Eds.), The new institutionalism in organizational analysis: 108-140. Chicago: University of Chicago Press. 
Strauss, A., \& Corbin, J. (1998). Basics of qualitative research techniques. Sage publications. Spillman, L. (2018). Meta-organization matters. Journal of Management Inquiry, 27(1), 1620.

Suchman, M. C. (1995). Managing Legitimacy: Strategic and Institutional Approaches. The Academy of Management Review, 20(3), 571.

Wang, P. (2010). Restructuring to Repair Legitimacy - A Contingency Perspective. Corporate Governance: An International Review, 18(1), 6-82.

Young, D. R. (2001). Organizational identity and the structure of nonprofit umbrella associations. Nonprofit Management and Leadership, 11(3), 289-304.

Zilber, T. B. (2008). The work of meanings in institutional processes. The SAGE handbook of organizational institutionalism, 151-168. 